\section{Is there still a role for abdominal plain X-ray in acute abdomen?}

\author{
Ciro Paolillo, ${ }^{1}$ Ilenia Spallino, ${ }^{1}$ \\ Gianfranco Cervellin, ${ }^{2}$ Fausto Catena ${ }^{3}$ \\ 'Emergency Department, Udine \\ University Hospital, Udine; ${ }^{2}$ Emergency \\ Department, Parma University Hospital, \\ Parma; ${ }^{3}$ Emergency Surgery Department, \\ Parma University Hospital, Parma, Italy
}

\begin{abstract}
The imaging workup of patients with acute abdominal pain still starts with abdominal Xray in several clinical settings and facilities. Unfortunately, conventional plain film is of limited utility if performed as a routine investigation. Abdominal radiography is valuable only in patients with suspected perforated viscus and large bowel obstruction. Ultrasound is mostly valuable in the vast majority of abdominal pain presentations, whereas computed tomography scan should be considered as second level test.
\end{abstract}

\section{Introduction}

Approximately 10\% of emergency department visits are due to acute abdominal pain, making it one of the most encountered complaints. $^{1-3}$

Several studies have demonstrated that a diagnosis based solely on a patient's medical history, physical examination, and laboratory tests is not reliable enough, despite the fact that these aspects are essential parts of the workup of a patient presenting with acute abdominal pain. ${ }^{4}$ Imaging workup traditionally starts with abdominal radiography series: supine and upright abdominal and erect chest radiography. Unfortunately, X-ray has limited utility in abdominal imaging. In 2011 the van Randen's group ${ }^{5}$ published the results of a multicenter prospective trial. The study compared the initial diagnosis, after clinical evaluation alone, with the final diagnosis, in patients with abdominal pain presented at the ED. The primary clinical diagnosis corresponded with the final diagnosis in less than half patients. After radiographs, primary diagnosis corresponded with final diagnosis in half cases; the improvement in accuracy of plain abdominal radiography combined with clinical examination was not significant $(\mathrm{P}=0.14)$. Treating physician changed primary diagnosis from initial clinical diagnosis in $11 \%$ after plain abdominal radiography, and these changes were accurate in only $22 \%$ of the patients. This study showed that clinical diagnosis after routine plain radiographs did not change significantly the primary diagnosis based on clinical evaluation alone. The Authors concluded that plain radiography should be omitted from routine diagnostic workup. The American College of Radiology, The Royal College of Radiologists and the Italian Society of Radiology, published indications for abdominal radiography that include only suspicion of perforated viscus or bowel obstruction. ${ }^{6-8}$

\section{Detection of free air}

The identification of a small amount of free intra-abdominal gas remains one of the most significant signs in medicine. Advocates of conventional radiography state that plain abdominal X-ray should be the first diagnostic modality used in suspicion of a perforated viscus. With a well done radiographic technique it is possible to detect small quantities of free gas, but a great experience is necessary. In Baker 's study, ${ }^{9}$ plain radiography demonstrated pneumoperitoneum in only $51 \%$ of the patients with documented visceral perforation. Van Randen ${ }^{5}$ found a sensitivity of plain radiographs for perforated viscus of only $15 \%$. Furthermore, when in reports of 1980 s plain radiographs typically revealed free intraperitoneal air originated from perforated peptic ulcers (59-69\%) or colonic diverticulitis (37$46 \%$ ), in recent years an increase of small bowel and colon perforation and a decline in the incidence of gastroduodenal perforation has seen, as the Kumar's study evidenced in $2012 .{ }^{10}$ If abdominal X-ray evidences a massive pneumoperitoneum other imaging are unnecessary. If plain radiography delineates minimal pneumoperitoneum and the clinical is not clear an additional computed tomography (CT) scan is often needed to adopt the specific operative strategy.

\section{Bowel obstruction}

Clinical findings in bowel obstruction include crampy abdominal pain, distension, increased bowel sounds and vomiting.

The results of a prospective study published in $1998^{4}$ evidenced that the combination of that variables has low sensitivity. Furthermore history and clinical examination are neither sufficiently sensitive nor specific to determine a coexistent ischemia. This uncertainty has led to the widespread use of imaging, above all to detect complication.

If there is a suspect of bowel obstruction the diagnostic evaluation should focus on the following goals: distinguishing mechanical obstruction from ileus; determining the etiolo-
Correspondence: Ciro Paolillo, Emergency Department, Udine University Hospital, piazzale Santa Maria della Misericordia 15, 33100 Udine, Italy.

Tel: +39.0432 .552360$

E-mail: ciropaolillo@gmail.com

Key words: Abdominal X ray; Acute abdomen; Plain radiography; Bowel occlusion; Pneumoperitoneum.

Conflict of interest: the authors declare no potential conflict of interest.

Received for publication: 22 September 2015. Revision received: 19 November 2015.

Accepted for publication: 27 November 2015.

This work is licensed under a Creative Commons Attribution 3.0 License (by-nc 3.0).

(C) Copyright C. Paolillo et al., 2015 Licensee PAGEPress, Italy

Emergency Care Journal 2015; 11:5528

doi:10.4081/ecj.2015.5528

gy of the obstruction; discriminating from partial to complete obstruction; and discriminating from simple to strangulating obstruction. $\mathrm{X}$-ray has conventionally been used as the first step in the diagnostic imaging evaluation of a patient with suspected bowel obstruction. ${ }^{11}$ The diagnostic accuracy of plain radiographs is low varying from 55 to $80 \%$. The diagnosis relies on two primary findings: dilated loops and air-fluid levels. Their evidence is correlated with the severity of obstruction (partial or complete) and with the time of onset until Xray is performed; an abdominal X-ray obtained just after the onset of the obstruction may not yet evidence dilated bowel proximal to the obstruction and may not yet evidence the absence of gas distal to the obstruction. Already the presence of more than two air-fluid level, air-fluid levels wider than $2.5 \mathrm{~cm}$, and air-fluid levels differing more than $5 \mathrm{~mm}$ from one another in the same small-bowel loop, have reported to be sensitive and specific to differentiate high-grade of small bowel obstruction from low grade. ${ }^{12}$ The sensitivity of the plain films is high when there is a high grade bowel obstruction, in this case X-ray is as sensitive as CT (86 vs $82 \%$ ). ${ }^{13}$ Unfortunately the number of symptomatic patients encountered with either low grade or no obstruction is considerably greater than the number of patients with a high-grade partial or complete bowel obstruction. In patients for whom clinical suspect of an intestinal obstruction is high and abdominal radiographs are insufficient to confidently confirm diagnosis or to reasonably assess the severity of obstruction, additional diagnostic imaging becomes necessary. 


\section{Conclusions}

The routinely use of abdominal X-ray as the first assessment after clinical examination in abdominal pain is striking considering the low diagnostic yield of this imaging test. ${ }^{14}$ However, performing abdominal CT in all patients presenting to the ED complaining for abdominal pain is an insane way, and it could be considered the Waterloo of the emergency system, indeed. So, is there still a role for abdominal plain X-ray in acute abdomen? The choice of imaging test is part of the strategy. ${ }^{15}$ After clinical evaluation, only in the suspect of perforation or bowel obstruction a plain radiography should be performed, while in different contests it is of poor value.

\section{References}

1. Gans SL, Pols MA, Stoker J, Boermeester MA. Guidelines for the diagnostic pathway in patients with acute abdominal pain. Digest Surg 2015;32:23-31.

2. McNamara R, Dean AJ. Approach to acute abdominal pain. Emerg Med Clin N Am 2011;29:159-73.
3. Gans SL, Stoker J, Boermeester MA. Plain abdominal radiography in acute abdominal pain; past, present, and future. Int $\mathrm{J}$ Gen Med 2012;4:525-33.

4. Bohner H, Yang Q, Franke Claus, et al. Simple data from history and physical examination help to exclude bowel obstruction and to avoid radiographic studies in patients with acute abdominal pain. Eur J Surg 1998;164:777-84.

5. Van Randen A, Laméris W, Luitse JSK, et al. The role of plain radiographs in patients with acute abdominal pain at the ED. Am J Emerg Med 2011;29:582-9.

6. American College of Radiology. ACR-SPR practice parameter for the performance of abdominal radiography. Available from: http://www.acr.org/ /media/79a594819bbd 4631a7e31404daa66ef6.pdf

7. Smith JE, Hall EJ. The use of plain abdominal $\mathrm{x}$ rays in the emergency department. Emerg Med J 2009;26:160-3.

8. Società Italiana di Radiologia Medica. SIRM guidelines. Available from: http://www. sirm.org/documenti/cat_view/ 66-linee-guida

9. Baker SR. Unenhanced helical CT versus plain abdominal radiography: a dissenting opinion. Radiology 1997;1:45-7.

10. Kumar A, Muir MT, Cohn SM, et al. The eti- ology of pneumoperitoneum in the 21st century. J Trauma Acute Care Surg 2012;73:542-8.

11. Rachel E, Musson, Bickle I, Ram KPV. Gas patterns on plain abdominal radiographs: a pictorial review. Postgrad Med J 2011;87:274-87.

12. Lappas JC, Reyes BL, Maglinte DD. Abdominal radiography findings in small bowel obstruction: relevance to triage for additional diagnostic imaging. Am J Roentgenol 2001; 176:167-74.

13. Magliette DD, Reyes BL, Harmron BH, et al. Reliability and role of plain film radiography and $\mathrm{CT}$ in the diagnosis of smallbowel obstruction. Am J Roentgenol 1996; 167:1451-5.

14. Morris-Stiff G, Stiff RE, Morris-Stiff H. Abdominal radiograph requesting in the setting of acute abdominal pain: temporal trends and appropriateness of requesting. Ann R Coll Surg Engl 2006;88:270-4.

15. Lameris W, van Randen A, van Es FW, et al. Imaging strategies for detection of urgent conditions in patients with acute abdominal pain: diagnostic accuracy study. Brit Med J 2009;339:2431. 